\title{
"Effect of Infant Feeding Practices on Nutritional Status of The Children Attending Out Patient Department of Shaheed Suhrawardi Hospital, Dhaka, Bangladesh"
}

\author{
Syeda Nafisa Islam ${ }^{1 *}$, Soofia Khatoon ${ }^{2}$, Md. Belal Uddin ${ }^{3}$, Sayeda Sunzida Sultana ${ }^{4}$, Md. Abu Sayed ${ }^{5}$
}

${ }^{1}$ Consultant, Department of Pediatrics, Rajsjahi Medical College Hospital, Rajshahi, Bangladesh

${ }^{2}$ Professor \& Head (Ex.), Dept. of Pediatrics, Shaheed Suhrawardi Medical College Hospital, Dhaka, Bangladesh

${ }^{3}$ Professor \& Head, Dept. of Pediatrics, Rajsjahi Medical College Hospital, Rajshahi, Bangladesh

${ }^{4}$ Consultant, Department of Pediatrics, Mymensingh Medical College, Mymensingh, Bangladesh

${ }^{5}$ Consultant, Department of Pediatrics, Sirajganj General Hospital, Sirajganj Sadar, Sirajganj, Bangladesh

DOI: $10.36347 /$ sjams.2021.v09i01.001

| Received: 07.12.2020 | Accepted: 29.12.2020 | Published: 04.01.2021

*Corresponding author: Syeda Nafisa Islam

Abstract

Original Research Article

Introduction: Global strategy of IYCF (Infant and Young Child Feeding) was approved by WHO and UNICEF IN 2000 for optimal growth and development of child. IYCF means both breast feeding and complementary feeding. Breast feeding is the best way of providing ideal food for infants. It results in improved infant and maternal health outcomes. Giving infants new appropriate foods along with breast milk is known as complementary feeding. Good complementary feeding practices are essential to protect infants and children from both under and over nutrition. Objectives: To determine infant and young child feeding (IYCF) practices along with their nutritional status of the fewer than 1 year children attended in Shaheed Suhrawardi Medical College Hospital, Dhaka, Bangladesh. Study Design: Descriptive type of cross sectional study. Study Setting and Period: Pediatric outpatient department and EPI centre of Shaheed Suhrawardi Medical College Hospital, Dhaka, from November 2010 to July 2011. Materials and Methods: Total 386 infants with their mother attending Pediatric outpatient department and EPI centre of Shaheed Suhrawardi Medical College Hospital were included in the study. Investigator herself interviewed the mother using a structured questionnaire. Feeding history of infants was collected from mothers using 24 hrs recall method. The height and weight of infants were measured. Results: Among 386, 52.3\% infants were under six months and $47.7 \%$ were between 6 months to 12 months of age. Some (6.7\%) infants were given Prelacteal feed, some (13\%) given only supplementary food. Exclusive breast feeding rate was high $(81 \%)$, as well as continued breast feeding $(86.3 \%)$. Timely complementary feeding started in majority (85\%) infants. In exclusive breast fed infants as well as infants who were given complementary feeding although the nutritional status was satisfactory, there was high prevalence of mild growth deficiency which may reflect inappropriate feeding status. Frequency and amount of both breast feeding and complementary feeding was not adequate. Conclusion: Although present study showed impressive results about feeding practices, but still there is growth deficiency. So we can improve growth status by more aggressive implementation of IYCF program.

Keywords: Breast Feeding, Infants, Nutritional Status, Mild Growth Deficiency, Supplementary Food.

Copyright $\odot 2021$ The Author(s): This is an open-access article distributed under the terms of the Creative Commons Attribution 4.0 International License (CC BY-NC 4.0) which permits unrestricted use, distribution, and reproduction in any medium for non-commercial use provided the original author and source are credited.

\section{INTRODUCTION}

Appropriate feeding practices are essential for proper nutrition, growth, development and survival of infant and young children. These feeding practices, which include both breast feeding and complementary feeding, are collectively known as Infant and young child feeding practice (IYCF). Global strategy of IYCF developed by WHO and UNICEF in 2000 to revitalize world attention on the impact of infant and young children feeding with the goal to protect, promote and support optimal infant and young child feeding practices[1]. The period from birth to 2 years is the "critical window" for the promotion of good growth, health, behavioral and cognitive development. Malnutrition has been responsible for over $50 \%$ deaths annually among children $<5$ years and over two thirds of these deaths occur in the first year of life. For optimal infant and young child feeding, infants should be (1) breast feed within an hour of birth (2) exclusive breast feeding for first six months of life (3) receive 
nutritionally adequate and safe complementary food (4) continued breast feeding up to 2 years and beyond. The Govt. of Bangladesh has also finalized 'National Strategy for Infant and young child feeding in Bangladesh' in 2007. The prioritized strategies for achievement of optimal IYCF in Bangladesh areStrategy 1- Code of marketing of breast milk substitutes, Strategy 2- Maternity protection in the workplace, Strategy 3-Codex standards, Strategy 4National policy and plans, Strategy 5-Baby friendly hospital initiative, Strategy 6- mainstreaming and prioritization of IYCF activities, Strategy 7-Knowledge and skills of health service providers, Strategy 8community based support for IYCF, strategy 9- IYCF in exceptionally difficult circumstances[2]. Mother ${ }^{\text {'s }}$ milk is best because of its nutritional, anti-infective, antiallergic, contraceptive and economic significance; it must be considered as a resource priority in the national development, health and family planning policies [3]. Breast feeding provides several important benefits to both infant and mother. It ensures nutrition, optimum growth and development, reduces morbidity and mortality of infants and also establishes bonding between mother and child. Infant feeding practices are associated with the context of ethnic and cultural beliefs, also depends on urban and rural people, working and non-working mother, affluent and nonaffluent people and mode of delivery etc [3, 4]. Bangladesh has strong cultural practices for breast feeding. Although the current situation is not satisfactory [5]. Now $42 \%$ of newborn are breast feed within 1 hour of birth, rate of exclusive breastfeeding is $64 \%$ and continued breast feeding is $90 \%$ [6]. Exclusive breastfeeding ensures that the infant receives the full nutritional and other advantages of breast milk, including developmental benefits and protection against infection and some chronic diseases [7]. Although promotion of proper breastfeeding practices for the first six months of life is the most cost-effective intervention for reducing childhood morbidity and mortality. However, the adherence to breastfeeding recommendations in many developing countries is not satisfactory. Despite the high proportion of mothers who initiated breastfeeding immediately after birth, continuation of exclusive breastfeeding for up to six months was not common in Nepal because very few mothers received any information on breastfeeding during the antenatal visit [8]. Usually mothers can successfully breastfeed their infants. While mothers may encounter difficulties with initiating and establishing breastfeeding, appropriate and effective positioning at the breast and correct attachment and milking action are the keys to successful breastfeeding. Antenatal education on positioning and attachment technique can be given, together with initiating breastfeeding soon after birth and providing continuing postnatal support and guidance. Health workers can provide invaluable help by offering factual information and empathetic support, demonstrating practical skills, and discussing strategies for problem solving [7].
Besides breastfeeding complementary feeding is also very important. Complementary feeding is the process starting when breast milk alone is no longer sufficient to meet the nutritional requirements of an infant and when other foods and liquids along with breast milk are needed after completion of six months of age [9]. Inappropriate infant and young child feeding practices are a major cause of the onset of malnutrition in young children [4, 5]. Children who are not breast fed appropriately have repeated infections, grow less well, and are almost six times more likely to die by the age of one month than children who receive at least some breast milk [10]. Infants are particularly vulnerable during the transitional period when complementary feeding begins. Good complementary feeding practices are essential to protect infants and children from both under and over nutrition [4]. Proper feeding practices during infancy are also essential for attaining and maintaining proper nutrition, health and development of infants and children. Inappropriate feeding practices can have profound consequences for the growth, development, and survival of infants and children, particularly in developing countries. More appropriate feeding practices are associated with greater gain in weight and length during infancy [5]. In rural Bangladesh $90 \%$ of girls and boys are below $5^{\text {th }}$ percentile of the NCHS reference standards. Some of the growth deficit is likely due to poor diets and feeding practices. Severely undernourished mothers produce insufficient quantities of breast milk to meet the needs of children, and complementary feeding fails to make up the nutrient deficit. Traditionally Bangladeshi woman do not persistently encourage their infants to eat other foods until 18 to 24 months [11]. Deprivation of breastfeeding and improper complementary feeding are significant risk factors for under nutrition among under five children. One study showed the picture of these infants- $36.4 \%$ were $<2$ SD for weight for age, $51.6 \%$ were $<2$ SD for height for age, $10.6 \%$ were $<2$ SD for weight for height [12]. Recent research has shown that under-five mortality can be reduced by $13 \%$ with optimal breastfeeding and a further $6 \%$ with optimal complementary feeding [4]. The optimal complementary foods should be started when child completed 6 months of life and adequate that meets a growing child's nutritional needs and safe which means hygienic food \& feeding process and no bottles and teats. Complementary feed should be responsive also [4]. One study showed $44.4 \%$ of babies were given complementary feeding before 6 months of age and timely complementary feeding was given in $60 \%$ of infants [9]. Another study showed length for age and weight for length were significantly lower among infants supplemented with millet gruel while no such relationship was found with family diet [13]. 


\section{OBJECTIVES}

\section{General objective}

1. To determine Infant and young child feeding practices along with their nutritional status and to determine if there is any relationship between them.

\section{Specific objectives}

1. To determine exclusive breastfeeding status of Infants below 6 months of age.

2. To determine continued breastfeeding status of Infants between 6 to 12 months of age.

3. To determine complementary feeding status of infants attending outpatient department.

4. To asses and classify growth status of these infants according to WHO standard.

5. To determine any relation of feeding status with growth status of these Infant.

\section{Materials ANd Methods}

Descriptive type of cross sectional study was carried out in Pediatric outpatient department and EPI centre of Shaheed Suhrawardi Medical College Hospital, Dhaka, Bangladesh from November 2010 to July 2011. Total 386 infants with their mother attending Pediatric outpatient department and EPI centre of Shaheed Suhrawardi Medical College Hospital were included in the study. Investigator herself interviewed the mother using a structured questionnaire. Feeding history of infants was collected from mothers using 24 hrs recall method. The height and weight of infants were measured.

\section{Inclusion criteria}

a) Children up to one year of age.

\section{Exclusion criteria}

a) Very sick children (features of very severe disease)

b) Mother unwilling to participate in the study.

\section{DATA ANALYSiS}

After editing and coding, the coded data was directly entered into the computer by using SPSS software release for Windows, version 16.0 (SPSS, Inc. Chicago. III). Data cleaning validation and analysis was performed using the SPSS software. Categorical data was presented as frequency, percentage and continuous variable was expressed as mean \pm SD (standard deviation).

\section{RESULTS}

A total of 386 infants (1 to 12 months) were included in this study who visited in SHSMCH, Dhaka, Bangladesh during the study period. Demographic profiles of the infants showed two age group, among them 202 infants were under six months and 184 were between 6 months to 12 months of age (fig 1). Distribution was not homogenous among different age groups. About one fourth $(28.5 \%)$ of the infants aged belonged to 3-4 months of age, one third (31.6\%) infants were belonging to 7-8 month age group (Table
1). Regarding sex male was predominant and male female ratio was 1.4:1. Feeding status revealed satisfactory result regarding exclusive breast feeding $(80 \%)$, although some $(13.7 \%)$ infants were given no breast milk at all. A good number $(85.5 \%)$ of infants started complementary feeding along with breast feeding timely but very few $(6.9 \%)$ started CF earlier (Table 3). Breast feeding frequency was also appropriate in majority $(94.32 \%)$ infants in age group $<6$ months. As 53 infants (26 were $<6$ month and 27 were $>6$ month) never breast fed, so they were not included in table 4. But regarding complementary feeding only one third of infants were at appropriate frequency although amount of SF / CF was not appropriate for majority infants in both age groups (Table 5, 6). As 162 infants were exclusively breast fed, so they were not included in Table 5. Regarding food that was given to the infants it was observed that in $\leq 6$ months of age majority $(80.1 \%)$ infants were given exclusive breast milk and in both age group breast milk was major food component. All infants' $\geq 6$ months received rice, dal, fish, and egg. Meat and fruit was given in $52.7 \%$ infant. Oil was used during cooking. Suzi made by adding sugar and cow or formula milk. Formula milk was given in $14 \%$ and $50.5 \%$ in age group $\leq 6$ months and $>6$ months respectively. About one fifth $(17.4 \%)$ mother fed with a bottle and teat. Few infants $(6.7 \%)$ were given prelacteal feed, other received only colostrum. But continued breast feeding rate up to one year of age was high (86.3\%), (fig 4).

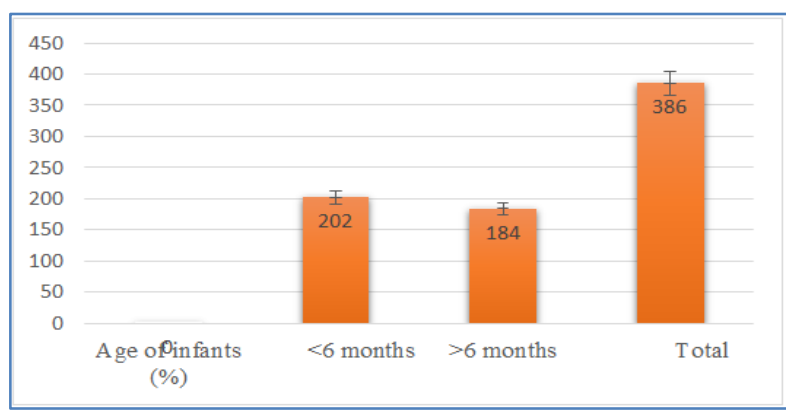

Fig-1: Distribution of the study infants by age below and above 6months

Table-1: Distribution of the study infants by age in month $(n=386)$

\begin{tabular}{|l|l|l|}
\hline Age(month) & Number & Percentage \\
\hline 1 & 11 & 2.8 \\
\hline 2 & 45 & 11.7 \\
\hline 3 & 65 & 16.8 \\
\hline 4 & 26 & 6.7 \\
\hline 5 & 28 & 7.3 \\
\hline 6 & 27 & 7.0 \\
\hline 7 & 80 & 20.7 \\
\hline 8 & 42 & 10.9 \\
\hline 9 & 12 & 3.1 \\
\hline 10 & 22 & 5.7 \\
\hline 11 & 19 & 4.9 \\
\hline 12 & 9 & 2.3 \\
\hline Total & 386 & 100.0 \\
\hline
\end{tabular}


Table-2: Distribution of the study infants by sex $(n=386)$

\begin{tabular}{|l|l|l|}
\hline Sex & Number of infants & Percentage (\%) \\
\hline Male & 225 & $58.3(\%)$ \\
\hline female & 161 & $41.7(\%)$ \\
\hline
\end{tabular}

Table-3: Distribution of infants $\leq 6$ months and $>6$ months by feeding status $(n=386)$

\begin{tabular}{|c|c|c|c|c|c|}
\hline \multirow{3}{*}{ Feeding status } & \multicolumn{5}{|c|}{ Age (months) } \\
\hline & \multicolumn{2}{|c|}{$\leq 6$ (Months) $(n=202)$} & \multicolumn{2}{|c|}{$>6($ Months $) \quad(n=184)$} & \multirow[b]{2}{*}{ Total } \\
\hline & $\mathrm{N}$ & $\%$ & $\mathrm{~N}$ & $\%$ & \\
\hline $\begin{array}{l}\text { Exclusive breast feeding } \\
\text { supplementary feeding (no breast feeding) }\end{array}$ & $\begin{array}{l}162 \\
26\end{array}$ & $\begin{array}{l}80.1 \\
12.8\end{array}$ & $\begin{array}{l}0 \\
0\end{array}$ & $\begin{array}{l}0 \\
0\end{array}$ & $\begin{array}{l}162 \\
26\end{array}$ \\
\hline Only complementary feeding & 0 & 0 & 27 & 14.6 & 27 \\
\hline Breast feeding and supplementary feeding & 14 & 6.9 & 0 & 0 & 14 \\
\hline Breast feeding and complementary feeding & 0 & 0 & 157 & 85.3 & 157 \\
\hline
\end{tabular}

Table-4: Distribution of infants by frequency of breast feeding in last $24 \mathrm{hrs}(\mathrm{n}=\mathbf{3 3 3})$

\begin{tabular}{|c|c|c|c|c|}
\hline & \multicolumn{4}{|c|}{ Age (months) } \\
\hline \multirow[t]{2}{*}{ Frequency of breast feeding } & \multicolumn{2}{|c|}{$\leq 6$ (Months) $N=176$} & \multicolumn{2}{|c|}{$>6$ (Months) $N=157$} \\
\hline & $\mathrm{N}$ & $\%$ & $\mathrm{~N}$ & $\%$ \\
\hline$<8$ Times & 10 & 507 & 125 & 79.6 \\
\hline$>8$ times & 166 & 94.3 & 32 & 20.4 \\
\hline
\end{tabular}

Table-5: Distribution of infants by frequency of supplementary / complementary feeding in last 24 hrs $(\mathrm{n}=\mathbf{2 2 4})$

\begin{tabular}{|l|l|l|l|l|}
\hline \multirow{2}{*}{ Frequency of supplementary / complementary feeding } & \multicolumn{4}{|l|}{ Age (months) } \\
\cline { 2 - 6 } & \multicolumn{2}{|l|}{$\mathbf{N}$ months } & \multicolumn{2}{l|}{$>\mathbf{6}$ months } \\
\hline$<4$ times & 18 & 45 & 122 & 66.3 \\
\hline$\geq 4$ times & 22 & 55 & 62 & 33.7 \\
\hline Total & 40 & 100 & 184 & 100 \\
\hline
\end{tabular}

Table-6: Distribution of infants by amount of supplementary / complementary feeding in last $24 \mathrm{hrs}(\mathrm{n}=\mathbf{2 2 4})$

\begin{tabular}{|l|l|l|l|l|}
\hline & \multicolumn{2}{l|}{ Age in months } \\
\hline $\begin{array}{l}\text { Amount of or supplementary } / \\
\text { complementary feed/day }\end{array}$ & \multicolumn{2}{l|}{$\leq \mathbf{6}$ (Months) $\mathbf{N = 4 0}$} & \multicolumn{2}{l|}{$>\mathbf{6}$ (Months) $\mathbf{N}=184$} \\
\hline & $\mathrm{n}$ & $\%$ & $\mathrm{~N}$ & $\%$ \\
\hline$\leq 3 \mathrm{cups} / 1 / 2$ bati & 19 & 47.5 & 110 & 59.7 \\
\hline$>3 \mathrm{cups} / 1 / 2$ bati & 21 & 52.5 & 74 & 40.3 \\
\hline
\end{tabular}

Table-7: Distribution of infants by type of food given in last $24 \mathrm{hrs}$

\begin{tabular}{|l|l|l|l|l|}
\hline \multirow{2}{*}{ Type of food given in last 24 hour } & \multicolumn{1}{|c|}{ months $(\mathbf{n}=\mathbf{2 0 2})$} & & $\mathbf{> 6 m o n t h} \mathbf{~ ( n = 1 8 4 )}$ & \\
\cline { 2 - 5 } & $\mathbf{N}$ & $\mathbf{\%}$ & $\mathbf{N}$ & \% \\
\hline Exclusive Breast milk & 162 & 80.1 & 0 & 0 \\
\hline Breast milk & 176 & 87.1 & 177 & 96.1 \\
Rice & 1 & 0.4 & 184 & 100 \\
Dal & 1 & 0.4 & 184 & 100 \\
Muri & 2 & 0.8 & 184 & 100 \\
Egg & 2 & 0.8 & 184 & 100 \\
\hline Suji & 13 & 6 & 67 & 36 \\
\hline Khichuri & 8 & 3 & 158 & 85.8 \\
\hline Fish & 0 & 0 & 4 & 2.1 \\
\hline Meat & 0 & 0 & 97 & 52.7 \\
\hline Cow milk & 11 & 5.4 & 13 & 7 \\
\hline Fruit & 0 & 0 & 97 & 52.7 \\
\hline Formula milk & 29 & 14 & 93 & 50.5 \\
\hline
\end{tabular}




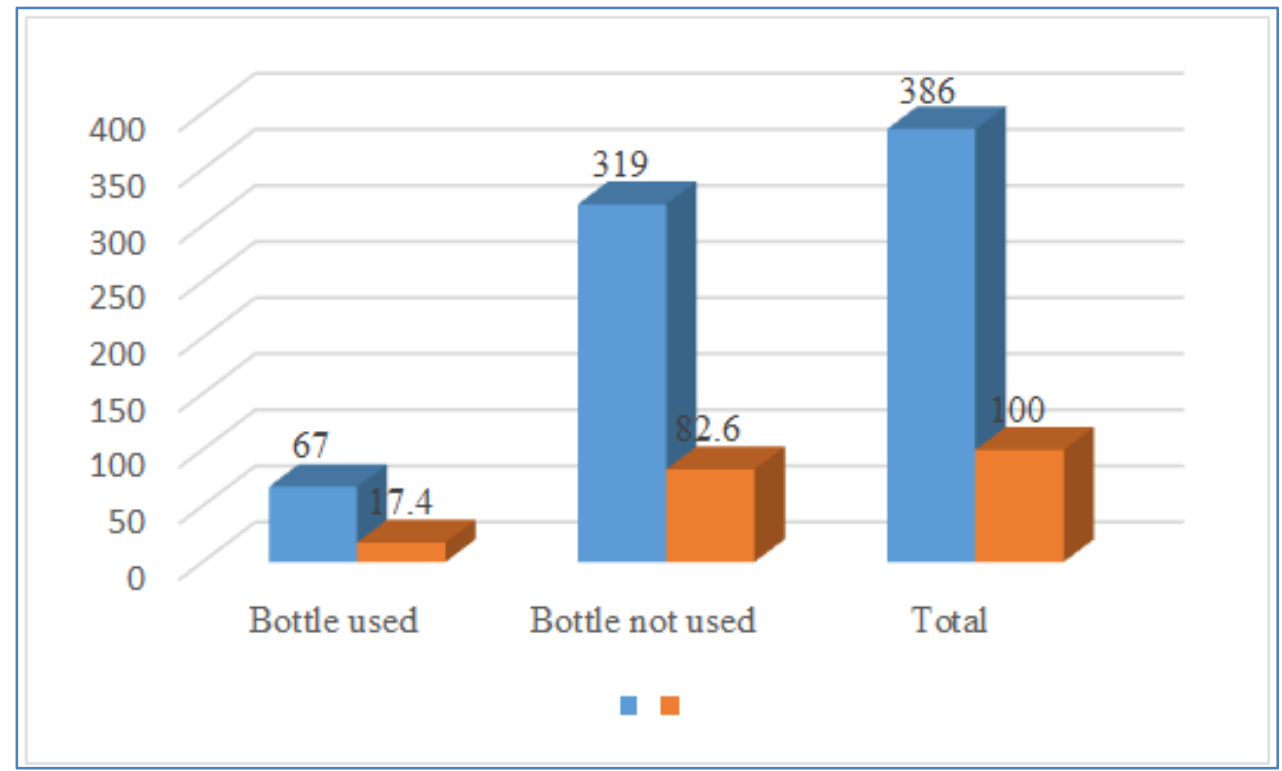

Fig-2: Distribution of infants by using a bottle with a teat $(n=386)$

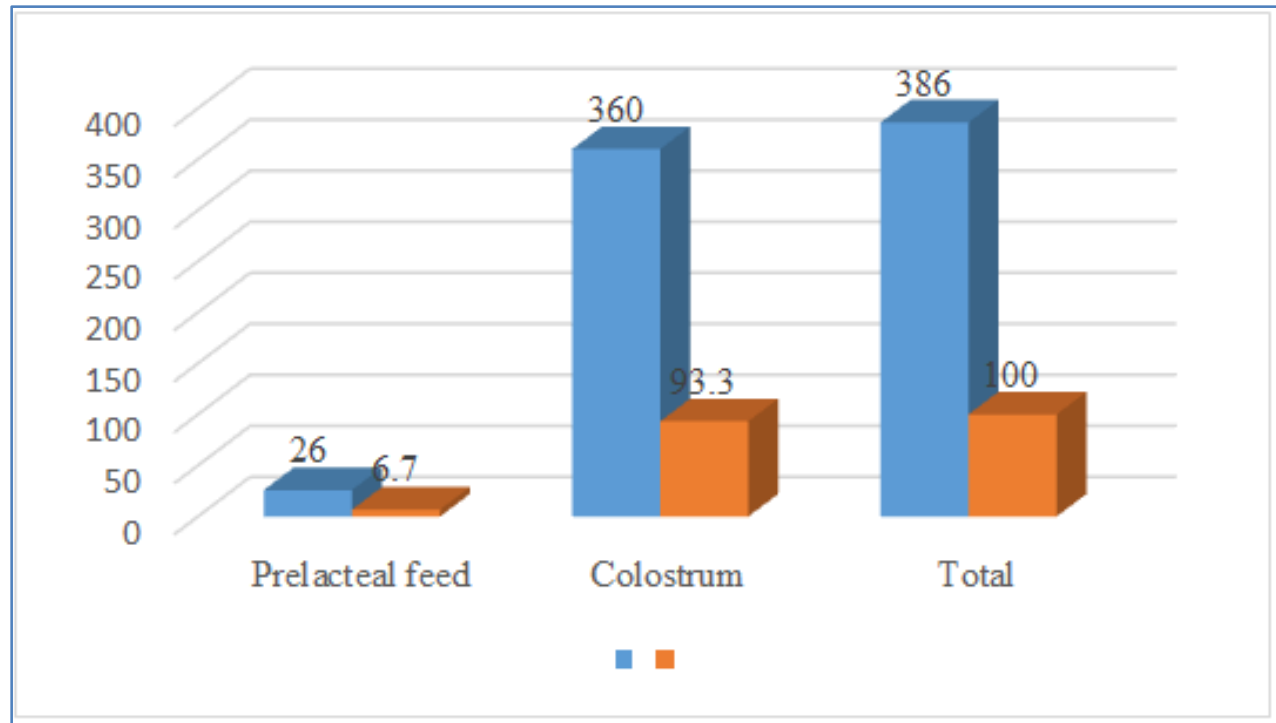

Fig-3: Distribution of infants by prelacteal and colostrum feeding

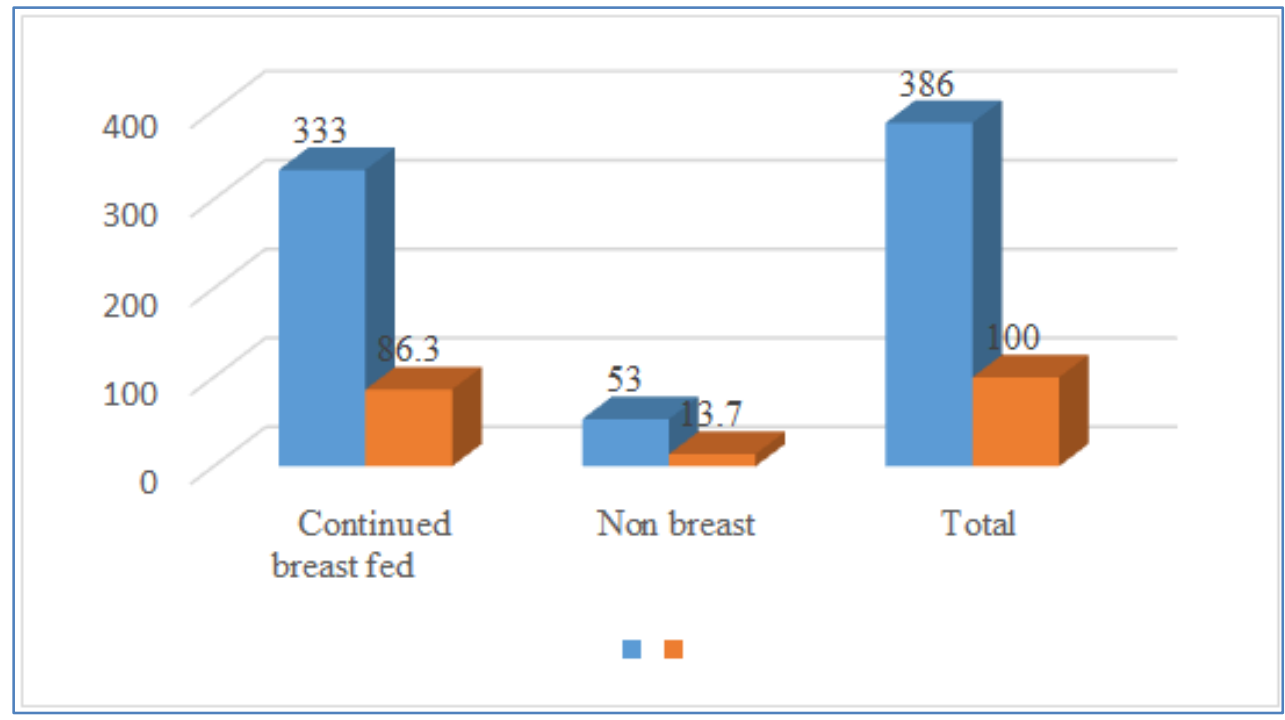

Fig-4: Distribution of infants by continued breast feeding rate $(n=386)$ 
Table-8: Distribution of infants nutritional status by $\mathrm{Z}$ score $(\mathrm{n}=386)$

\begin{tabular}{|c|c|c|c|c|}
\hline \multirow{2}{*}{$\begin{array}{l}\text { Nutritional status } \\
\text { Weight for Length }\end{array}$} & \multicolumn{2}{|c|}{$\leq 6$ Month $(n=202)$} & \multicolumn{2}{|c|}{$>6$ Month $(n=184)$} \\
\hline & $\mathrm{N}$ & $\%$ & $\mathrm{~N}$ & $\%$ \\
\hline+2 to $-1 \mathrm{Z}$ (normal) & 150 & 74.2 & 121 & 65.7 \\
\hline$>-1$ to $-2 Z$ (mild wasting) & 43 & 21.2 & 45 & 24.4 \\
\hline$>-2$ to $-3 Z$ (moderate wasting) & 9 & 4.4 & 17 & 9.2 \\
\hline$<-3 Z$ (severe wasting) & 0 & 0 & 1 & 0 \\
\hline \multicolumn{5}{|l|}{ Length for Age } \\
\hline+2 to $-1 \mathrm{Z}$ (normal) & 76 & 38.5 & 93 & 50.5 \\
\hline$>-1$ to $-2 Z$ (mild stunting) & 98 & 48.5 & 72 & 39.1 \\
\hline$>-2$ to $-3 Z$ (moderate stunting) & 26 & 12.8 & 18 & 9.7 \\
\hline$<-3 Z$ (severe stunting) & 2 & 0.9 & 1 & 0.5 \\
\hline \multicolumn{5}{|l|}{ Weight for Age } \\
\hline+2 to $-1 Z$ (normal $)$ & 68 & 33.6 & 76 & 41.3 \\
\hline$<-1$ to $-2 Z$ (mild underweight) & 89 & 44 & 77 & 41.8 \\
\hline$<-2$ to $-3 Z$ (moderate underweight ) & 44 & 12.7 & 26 & 14.1 \\
\hline$<-3 Z$ (severe underweight) & 1 & 0.4 & 5 & 2.7 \\
\hline
\end{tabular}

Table-9: Distribution of $\leq 6$ month infant by WAZ with different feeding practices $(n=202)$

\begin{tabular}{|l|l|l|l|l|l|l|}
\hline \multirow{2}{*}{$\begin{array}{l}\text { Weight } \\
\text { for age (under nutrition) }\end{array}$} & \multicolumn{6}{l|}{ Feeding status } \\
\cline { 2 - 8 } & \multicolumn{2}{|l|}{ EBF(162) } & \multicolumn{2}{l|}{ Only SF (26) } & \multicolumn{2}{l|}{ Both BF+SF (14) } \\
\cline { 2 - 8 } & $\mathrm{N}$ & $\%$ & $\mathrm{~N}$ & $\%$ & $\mathrm{~N}$ & $\%$ \\
\hline normal & 67 & 41 & 1 & 3.8 & 0 & 0 \\
\hline Mild & 75 & 46 & 10 & 38 & 4 & 28.5 \\
\hline moderate & 20 & 12 & 14 & 53 & 10 & 71.4 \\
\hline severe & 0 & 0 & 1 & 3.8 & 0 & 0 \\
\hline
\end{tabular}

Table-10: Distribution of $>6$ month infant by WAZ with different feeding practices $(n=184)$

\begin{tabular}{|l|l|l|l|l|l|l|}
\hline \multirow{2}{*}{$\begin{array}{l}\text { Weight } \\
\text { for age (under nutrition) }\end{array}$} & \multicolumn{6}{|l|}{ Feeding status } \\
\cline { 2 - 7 } & $\mathbf{E B F}(\mathbf{0})$ & \multicolumn{2}{l|}{ Only CF (27) } & \multicolumn{2}{l|}{ Both (157) (BF +CF) } \\
\cline { 2 - 7 } & $\mathrm{N}$ & $\%$ & $\mathrm{~N}$ & $\%$ & $\mathrm{~N}$ & $\%$ \\
\hline normal & 0 & 0 & 0 & 0 & 76 & 48.4 \\
\hline mild & 0 & 0 & 7 & 25.9 & 70 & 44.4 \\
\hline moderate & 0 & 0 & 15 & 55.5 & 11 & 7 \\
\hline severe & 0 & 0 & 5 & 18.5 & 0 & 0 \\
\hline
\end{tabular}

Table-11: Distribution of $\leq 6$ months infant by LAZ having different feeding practices $(\mathrm{n}=202)$

\begin{tabular}{|l|l|l|l|l|l|l|}
\hline $\begin{array}{l}\text { Lenght } \\
\text { for age (stunting) }\end{array}$ & \multicolumn{6}{|l|}{ Feeding status } \\
\hline & EBF (0) & \multicolumn{2}{l|}{ Only SF (26) } & Both (14) BF+SF \\
\hline & $\mathrm{N}$ & $\%$ & $\mathrm{~N}$ & $\%$ & $\mathrm{~N}$ & $\%$ \\
\hline normal & 70 & 43 & 4 & 15.3 & 2 & 14.2 \\
\hline mild & 80 & 49 & 10 & 38.4 & 8 & 57.1 \\
\hline moderate & 12 & 7.4 & 12 & 46.1 & 2 & 14.2 \\
\hline severe & 0 & 0 & 0 & 0 & 2 & 14.2 \\
\hline
\end{tabular}

Table-12: Distribution of >6 months infant by LAZ having different feeding practices $(\mathrm{n}=184)$

\begin{tabular}{|c|c|c|c|c|c|c|}
\hline \multirow{3}{*}{$\begin{array}{l}\text { Lenght } \\
\text { for age (stunting) }\end{array}$} & \multicolumn{6}{|c|}{ Feeding status } \\
\hline & \multicolumn{2}{|c|}{ EBF (0) } & \multicolumn{2}{|c|}{ Only CF (27) } & \multicolumn{2}{|c|}{ Both BF+CF (157) } \\
\hline & $\mathrm{N}$ & $\%$ & $\mathrm{~N}$ & $\%$ & $\mathrm{~N}$ & $\%$ \\
\hline normal & 0 & 0 & 8 & 29.6 & 85 & 54.1 \\
\hline mild & 0 & 0 & 7 & 25.9 & 65 & 41.4 \\
\hline moderate & 0 & 0 & 11 & 40.7 & 7 & 4.4 \\
\hline severe & 0 & 0 & 1 & 3.7 & 0 & 0 \\
\hline
\end{tabular}


Table-13: Distribution of $\leq 6$ months infant by WAL having different feeding practices $(\mathbf{n}=202)$

\begin{tabular}{|l|l|l|l|l|l|l|}
\hline \multirow{2}{*}{$\begin{array}{l}\text { Weight } \\
\text { For length (Wasting) }\end{array}$} & \multicolumn{9}{c|}{ Feeding status } & \multicolumn{2}{c|}{ Both } \\
\cline { 2 - 8 } & \multicolumn{2}{|c|}{ EBF (n=162) } & \multicolumn{2}{c|}{ Only SF (n=26) } & \multicolumn{2}{|c|}{ SF+BF (n=14) } \\
\cline { 2 - 8 } & $\mathrm{N}$ & $\%$ & $\mathrm{~N}$ & $\%$ & $\mathrm{~N}$ & $\%$ \\
\hline Normal & 136 & 83.9 & 8 & 30.7 & 6 & 42.8 \\
\hline Mild & 23 & 14.1 & 14 & 53.8 & 6 & 42.8 \\
\hline Moderate & 3 & 1.8 & 4 & 15.3 & 2 & 14.2 \\
\hline Severe & 0 & 0 & 0 & 0 & 0 & 0 \\
\hline
\end{tabular}

Table-14: Distribution of > 6 months infant by WAL having different feeding practices $(\mathrm{N}=184)$

\begin{tabular}{|l|l|l|l|l|l|l|}
\hline \multirow{2}{*}{$\begin{array}{l}\text { Weight } \\
\text { for length (wasting) }\end{array}$} & \multicolumn{6}{|c|}{ Feeding status } \\
\cline { 2 - 8 } & \multicolumn{2}{|c|}{ EBF (n=0) } & \multicolumn{2}{c|}{ Only CF (n=27) } & \multicolumn{2}{l|}{ Both (n=157) BF+CF } \\
\cline { 2 - 8 } & $\mathrm{N}$ & $\%$ & $\mathrm{~N}$ & $\%$ & $\mathrm{~N}$ & $\%$ \\
\hline normal & 0 & 0 & 6 & 22.2 & 115 & 73.2 \\
\hline mild & 0 & 0 & 14 & 51.8 & 31 & 19.7 \\
\hline moderate & 0 & 0 & 6 & 22.2 & 11 & 7 \\
\hline severe & 0 & 0 & 1 & 3.7 & 0 & 0 \\
\hline
\end{tabular}

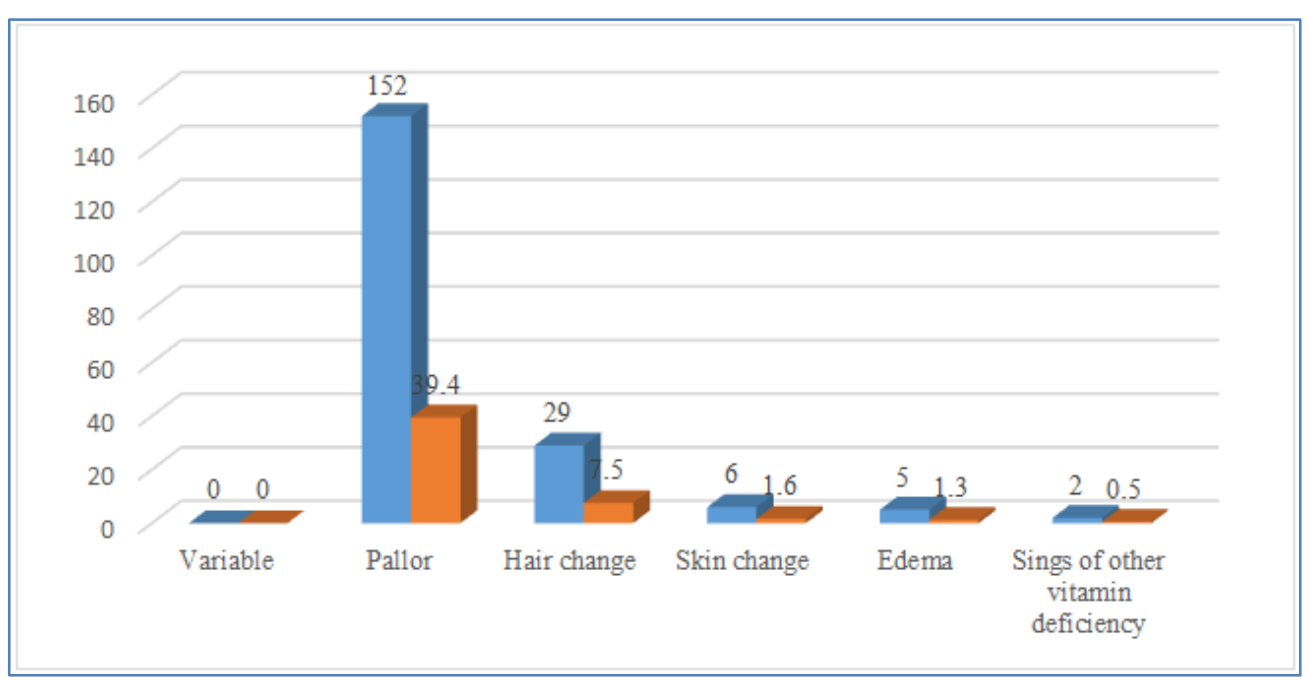

Fig-5: Distribution of infants having other signs of malnutrition $(n=386)$

Regarding nutritional status based on $\mathrm{Z}$ score (WHO) of the study infants, it was observed that wellnourished was common in weight for length of both age group, which was $74.2 \%$ in $\leq 6$ months and $65.7 \%$ in $>6$ months. In $\leq 6$ month age group undernutrition and stunting of different grade was more but no severe wasting was seen (Table 8). Weight for age $\mathrm{Z}$ score $\leq 6$ months of age showed proportion of normal and mild undernutrition was nearly equal among 162 exclusively breast fed infants but moderate underweight was more in infants who were given only SF (53\%) and also in both breast feeding and supplementary feeding group (71.4\%), (Table 9). Weight for age $\mathrm{Z}$ score $>6$ months of age, showed no one was exclusively breast fed but still moderate undernutrition was higher in only complementary feed group and no severely underweight was seen in infants who fed both breast milk and complementary food (Table 10). Length for age among 162 exclusively breast fed infant was normal in $\mathrm{Z}$ score $43 \%$ and no one was severely stunted in contrary to only SF fed baby where majority $(46.1 \%)$ were moderately stunted. Infants who fed breast milk and supplementary food, $14.2 \%$ were severely stunted
(Table 11). No mother delayed to start complementary feeding that is no infant was exclusively breast fed in > 6 months age group. Among 27 only SF babies majority $(40.7 \%)$ were moderately stunted in exchange of infants who fed both breast milk and complementary food, mostly $(54.1 \%)$ were normal, no one was severely stunted (Table 12). Regarding weight for length $\mathrm{Z}$ score among 162 exclusively breast fed infants, a significant number $(83.9 \%)$ had normal but mild wasting was more common in only $\mathrm{SF}$ and both $\mathrm{BF}+\mathrm{SF}$ feed group in contrast to infant $>6$ months of age who fed both breast milk and complementary food majority $(73.2 \%)$ were normal and no one was severely wasted (Table 13, 14).

\section{DISCUSSION}

This descriptive type cross sectional study was carried out with an aim to determine infant feeding practices and their nutritional status and also to determine if there is any relationship between them. Growth status of the children measured according to WHO growth chart. The present study showed higher 
percent of children with normal nutritional status and mild malnutrition in those children who are exclusively breastfed or fed breast milk along with CF. These changes are visible both below and above 6 months of age infants. This finding may suggest protection effect of breast feeding from developing malnutrition. Present study showed high exclusive breast feeding (80.1\%) rate in under 6 months age as well as high breast feeding and complimentary feeding rate $(85.3 \%)$ in more than $6^{\text {th }}$ month's age group infants (Table 3 ). Few (6.7\%) infants were given Prelacteal food (Figure 2), other were given colostrums. BDHS data showed $90 \%$ of children were breastfed until age 2 year and $64 \%$ of children less than 6 months age were exclusively breastfed. Haque et al. showed $61.3 \%$ mother breast fed their children exclusively. Most of the mothers (92\%) fed colostrums to their babies [14]. Khatun and Siddiqua had undertaken a study to observe the patterns of infant feeding practice among the mothers of high and low socio-economic groups in Bangladesh [15]. The rate of exclusive breast feeding among mothers of 2-3 months baby from high socio-economic group was found $41.2 \%$ and low socio-economic group $34.4 \%$. From this study it was evident that mothers of low socioeconomic group have poor knowledge regarding the infant feeding practices. Iqbal Kabir, Mansura Khanam et al. worked for Determinants of inappropriate complementary feeding practices in infant and young children in Bangladesh [16]. Subba et al. found prevalence of breastfeeding was $99.4 \%$ and $60.5 \%$ were practicing exclusive breastfeeding at 5 months [8]. M. Burhan Uddin et al. showed $80 \%$ of Garo mothers and $89.4 \%$ of Non Garo mother gave colostrums to their babies respectively [20]. Khatun and Siddiqua showed colostrums giving practice, which was observed in 94.2\% mothers of high socio-economic group and $67.3 \%$ of low of socioeconomic group [15]. Despite apparently satisfactory feeding practice some (17.4\%) infants were given bottle with teat (Figure 2) but other study had no comment about this finding. Although $>6$ months of age group $100 \%$ infant received complementary feeding, few $(14,6.9 \%)$ infants started SF $<6$ months of age. Several other published studies showed some different results. M. Burhan Uddin et al. showed almost $87 \%$ of Garo and $84 \%$ Non Garo mothers started supplementary feeding before the recommended age of 6 months [20]. Haque M J et al. showed some mothers $(21.7 \%)$ weaned their child much earlier i.e.; before attaining the age of 4 months [14]. Subba et al. showed almost $40 \%$ of the mothers started supplementary feeding before the recommended age of 6 months and $22.5 \%$ delayed introduction of complementary feeding beyond the recommended age [8]. Siddarth et al. showed that at the start of the second year of life only about $42 \%$ of infants received the appropriate complementary foods at appropriate frequency [9]. BDHS data 2011 showed only $21 \%$ of children aged 6-23 months fed appropriate CF. Popular complementary food was rice, dal, egg and muri in $>6$ months age group in this study (Table - 7), which was similar to other study $[20,17,22]$. M. Burhan Uddin et al. showed Garo and non Garo mothers used complementary foods such as cow's milk, suzi, and rice in most of the infants, and it was served mostly one time in a day, some fed two to four times [20]. D. K. Paul et al. found in their study as a weaning food, $51.5 \%$ mother used mashed rice, only $6.5 \%$ used khichuri [17]. Basnet et al. documented in their study that $22 \%$ of the mothers were using infant formula [22]. But present study showed about half of the infant $>6$ months and few $(14 \%)<6$ months were given formula. Continued breast feeding rate was $86.3 \%$ (fig 4) in this study. Which was similar with data showed by $\mathrm{M}$. Burhan Uddin et al. where prevalence of breastfeeding was $95.6 \%$ in Garo mother and $97.2 \%$ in Non Garo mother [20]. In Bangladesh almost all children (100\%) are breastfed at some time in their lives and over $86 \%$ of children are still breastfed at 20-23 month of age [6]. Regarding nutritional status based on $\mathrm{Z}$ score (WHO), of the study infants it was observed that in both age groups majority infants were well nourished by weight for length $\mathrm{Z}$ score. Mild stunting and mild underweight was found in $48.5 \%$ and $44 \%$ respectively in $<6$ months age group which was slightly higher than $>6$ months age group (Table 8) and interestingly frequency of breast feeding was also adequate in $<6$ months. This cannot be explained how, but it may be speculated that each episode of breast feeding might not be of appropriate length and as the data collected by 24 hour recall method long term feeding status could not be evaluated here. This may be due to maternal malnutrition too. Mother may have failed to breast fed as they are undernourished or these mother are working mother or due to poverty they could not breastfed. As these conditions were not checked by the present study, so influences of these factors could not be evaluated. Furthermore complementary feeding was adequate only in $30 \%$ to $40 \%$ infants (Table-5, 6). This may explain mild growth retardation in $>6$ months infant. Apart from this no severe growth retardation was found in EBF group in $<6$ months age and both $\mathrm{BF}+\mathrm{CF}$ group in $>6$ months age. On the other hand infant fed only SF or $\mathrm{CF}$ in both age group majorities had moderate and some had severe growth retardation. In $<6$ months age group moderate undernutrition was 53\%, stunting $46 \%$, wasting $15 \%$ and in $>6$ months age group moderate undernutrition was $55 \%$, stunting $41 \%$, wasting $22 \%$. Wasting found relatively smaller percentage as both weight and height were decreased. BDHS 2011 showed $41 \%$ of children under 5 year were stunted, $16 \%$ were wasted, and $36 \%$ were underweight. Muaz et al. found in their survey, prevalence of wasting was $42.3 \%$ whereas that of stunting and underweight was $80.2 \%$ and $73 \%$ respectively [21]. Kumar et al. also found $51.6 \%$ stunting in their study [12]. M.A.Hannan et al. performed a national survey and results showed that $38.1 \%$ were stunted and $38 \%$ were under weight for their age. Overall, $46 \%$ of children were suffering from diseases [23]. Total 386 infants who attended in department of pediatrics (outpatient department and EPI 
center), Shaheed Suhrawardy Medical College and Hospital, (ShSMCH) Dhaka, during the period of November 2010 to July 2011 were included in this study. Infants were distributed into two groups (below and above 6 months). Although the age distributions were not homogeneous one third infants were belonging to 7 to 8 months of age. Regarding the sex of the infants it was observed in this study that male infants was predominant in number, where male to female ratio was 1.4: 1 (Table-2). Similar observations were also made by Khan et al. Ulak et al. Sarid and Shraga and Mushaphi in their study $[23,24,5]$. In contrast to previous study, stunting and wasting was found in smaller number in this study because we have included only children up to one year of age and very sick children were excluded from the study. Some other factors were also related. Infants attended to EPI center were mostly healthy and most of the infants lived nearby the hospital. ShSMH is a baby friendly hospital which may influence the feeding practices of infants in a positive way. We have found that, in $\leq 6$ month age group, among exclusively breast fed babies $41 \%$ had normal WAZ, $43 \%$ had normal LAZ and $83.9 \%$ had normal WLZ. Infants $>6$ month age group who were given both breast milk and complimentary food, $48 \%$ had normal WAZ, 54\% had normal LAZ and 73\% had normal WLZ. Compared to infants who fed only SF or $\mathrm{CF}$ and not breast fed at all or started SF earlier had moderate malnutrition in $>50 \%$ infants (Table 8 to 13). The findings are of particular importance in light of the recent suggestion that to improve the health status we should assure good infant feeding practice.

\section{CONCLUSION}

Although the present study shows some improvement regarding feeding practices that is colostrums given in $93.3 \%$, EBF rate was $80 \%$, continued breast feeding rate was $86 \%$, timely $\mathrm{CF}$ started in $93 \%$ infants. Exclusive breast feeding was more than national data, no mother delayed in starting complementary feeding but still there is significant mild growth retardation. So the finding of the present study demonstrates that appropriate feeding practices should be developed and practiced for better health and to achieve the IYCF goal.

\section{Limitations and Recommendation}

The current study has following limitations that need to be addressed. First: The questions were retrospective in nature; it is possible that the mother's recollections were not accurate. However this method of research is commonly used by other researchers and yields good results. Second: Only hospital based study has been done, community level picture has not reflected here.A country wide larger study including rural area is recommended for better conclusion.

\section{REFERENCES}

1. Global strategy for infant and young child feeding. Geneva: WHO; 2003.
2. National strategy for infant and young child in Bangladesh. Institute of Public Health Nutrition; 2007.

3. Khan MR, Rahman ME. Essence of Pediatrics, fourth edition. Reed Elsevier: India Private Limited; 2011.

4. Saha KK, Frongilo EA, Alam DS, Arifeen SE, Rasmussen KM. Appropriate infant feeding practices result in better growth of infants and young children in rural Bangladesh. American Journal of Clinical Nutrition. 2008; 87: 1852-9.

5. Musaphi LF, Mbhenyane XG, Khoza LB, Amey AKA. Infant feeding practices of mothers and nutritional status of infants in the Vhembe District of Limpopo Province. S Afr J Clin Nutr. 2008; 21(2):36-41

6. Bangladesh Demographic Health Survey data, National Institute of Population Research and Training; 2011.

7. Infant feeding guidelines for health workers, National Health and Medical Council of Australian Government; 2012.

8. Subba SH, Chandrashekhar TS, Binu VS, Joshi HS, Rana MS, Dixit SB. Infant feeding practices of mothers in an urban area in Nepal. Kathmandu University Medical Journal. 2007; 5(1): 42-47.

9. Siddarth Ramji's Impact of infant \& young child feeding \& caring practices on nutritional status \& health. Indian J Med Res. 2009; 130: 624-626.

10. National Food Policy Capacity Strengthening Programme: FAO, EU, USAID; 2012.

11. Brown LV, Peterson KE, Chowdhury AMR, Rogers BL, Weld LH, Gershoff SN. Evaluation of the impact of weaning food messages on infant feeding practices and child growth in rural Bangladesh. American Journal of Clinical Nutrition. 1992; 56: 994-1003.

12. Kumar D, Goel NK, Ponam C, Mittal and Purnima Misra. Influence of infant feeding practices on nutritional status of under-five children. Indian Journal of Pediatrics. 2006; 73(5), 417-421.

13. Simondon KB, Simondon F. Infant feeding and nutritional status dilemma of mothers in rural Senegal. European Journal of Clinical Nutrition. 1995; 49(3):179-88.

14. Haque MJ, Rahman MM, Sarker SK. Infant Feeding Practice by the Rural Mothers of Dinajpur District. Dinajpur Med Col J. 2010; 3 (1):35-38.

15. Khatun M, Siddiqua SA. Infant feeding practices among mothers of high and low socio economic group in selected areas of Dhaka city. Journal of Shaheed Suhrawardy Medical College. 2010; 2(1).

16. Kabir I, Khanam M, Kingsley EA, Shima M, Michael JD, Roy SK, Determinants of inappropriate complementary feeding practices in infant and young children in Bangladesh: secondary data analysis of Demographic Health Survey; 2007.

17. Paul DK, Rahman MS, Rahman MH, Toufiq ME, Prodhan UK. Infants feeding and weaning practices 
in slum dwellers of Jessore district in Bangladesh. Journal of socioechonomic research and development. 2009; 6(2): 552-557.

18. Zhang LL, Scott M Jane A, Binns CW, Collin WB. Infant feeding practices in home countries and Australia: Perth Chinese mothers survey. Nutrition $\&$ Dietetics. The Journal of the Dieticians Association of Australia. 2005; 62(1): 82-88.

19. Kamudoni P, Maleta K, Zumin S, Ottesen GH. Infant Feeding Practices in the First 6 Months and Associated Factors in a Rural and Semiurban Community in Mangochi District, Malawi. J Hum Lact. 2009; 23(4): 325-332.

20. BurhanUddin M, Rahman SMB, Hussain I. Infants Feeding Practices among Garo and non Garo Mothers from Netrakona District Bangladesh. World Journal of Medical Sciences. 2011; 6 (4): 202-208
21. Muaz SSA, Hasan MR, Shamim AS, Dev A, Kumar S. Nutritional Status of 1-5 Years Children of the Tea Workers in Sylhet Division. Bangladesh Journal of Child Health. 2010; 34 (1): 11-16.

22. Basnet S, Gauchan E, Malla K, Malla T, Koirala DP, Rao KS. Infant feeding practices in Kaski district, Pokhara. Journal of Nepal Pediatric Society. 2012; 32(1): 23-27.

23. Ulak M, Chandyo RK, Mellander L, Shreshtha PS, Strand TA. Infant feeding practices in Bhaktapur, Nepal: cross sectional health facility based survey. International breast feeding Journal. 2012; 7(1):1-8.

24. Sharid O, Shraga Y. Infants sleeping and feeding patterning: a cultural perspective on maternal practices. Journal of Nursing Education and Practice. 2013; V-3: 118-124. 